\title{
Patient-specific computational fluid dynamics—assessment of aortic hemodynamics in a spectrum of aortic valve pathologies
}

\author{
Pouya Youssefi, BSc(Hons), MBBS, MRCS(Eng), ${ }^{\text {a,b }}$ Alberto Gomez, PhD, ${ }^{\text {b }}$ Taigang He, PhD, \\ Lisa Anderson, MBBS, MRCP, ${ }^{\mathrm{a}}$ Nick Bunce, MBBS, MRCP, ${ }^{\mathrm{a}}$ Rajan Sharma, MBBS, MRCP, ${ }^{\mathrm{a}}$ \\ C. Alberto Figueroa, $\mathrm{PhD},{ }^{\mathrm{b}, \mathrm{c}}$ and Marjan Jahangiri, FRCS(CTh)
}

\begin{abstract}
Objectives: The complexity of aortic disease is not fully exposed by aortic dimensions alone, and morbidity or mortality can occur before intervention thresholds are met. Patient-specific computational fluid dynamics (CFD) were used to assess the effect of different aortic valve morphologies on velocity profiles, flow patterns, helicity, wall shear stress (WSS), and oscillatory shear index (OSI) in the thoracic aorta.
\end{abstract}

Methods: A total of 45 subjects were divided into 5 groups: volunteers, aortic regurgitation-tricuspid aortic valve (AR-TAV), aortic stenosis-tricuspid aortic valve (AS-TAV), aortic stenosis-bicuspid aortic valve right-left cusp fusion (BAV[RL]), and aortic stenosis-right-non cusp fusion (AS-BAV[RN]). Subjects underwent magnetic resonance angiography, with phase-contrast magnetic resonance imaging at the sino-tubular junction to define patient-specific inflow velocity profiles. Hemodynamic recordings were used alongside magnetic resonance imaging angiographic data to run patient-specific CFD.

Results: The BAV groups had larger mid-ascending aorta diameters $(P<.05)$. Ascending aorta flow was more eccentric in BAV (flow asymmetry $=78.9 \%$ $\pm 6.5 \%$ for $\mathrm{AS}-\mathrm{BAV}(\mathrm{RN})$, compared with $4.7 \% \pm 2.1 \%$ for volunteers, $P<.05)$. Helicity was greater in AS-BAV(RL) $(P<.05)$. Mean WSS was elevated in AS groups, greatest in AS-BAV(RN) $\left(37.1 \pm 4.0 \mathrm{dyn} / \mathrm{cm}^{2}\right.$, compared with $9.8 \pm 5.4$ for volunteers, $P<.05$ ). The greater curvature of the ascending aorta experienced highest WSS and lowest OSI in AS patients, most significant in $\operatorname{AS}-\mathrm{BAV}(\mathrm{RN})(P<.05)$.

Conclusions: BAV displays eccentric flow with high helicity. The presence of AS, particularly in BAV-RN, led to greater WSS and lower OSI in the greater curvature of the ascending aorta. Patient-specific CFD provides noninvasive functional assessment of the thoracic aorta, and may enable development of a personalized approach to diagnosis and management of aortic disease beyond traditional guidelines. (J Thorac Cardiovasc Surg 2017;153:8-20)

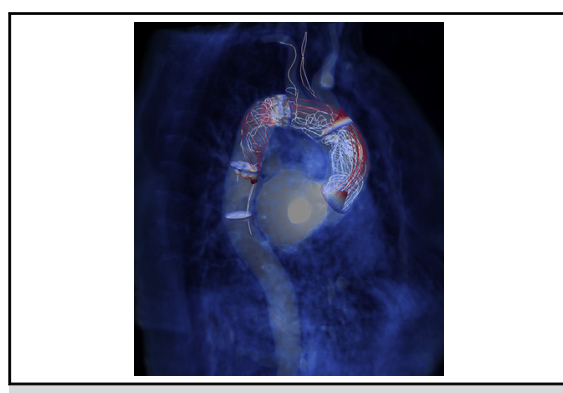

Aortic velocity streamlines and vectors for a patient with right-nonfusion bicuspid aortic valve.

\section{Central Message}

$\overline{\text { Patient-specific computational fluid dynamics }}$ reveals high wall shear stress and lower oscillatory shear index in the greater curvature of bicuspid aortic valve aortas, with highly eccentric and helical flow.

\section{Perspective}

In patients with aortic valve disease and aortic aneurysm, morbidity or mortality can occur before size criteria for intervention are met. Patientspecific computational fluid dynamics provides noninvasive functional and hemodynamic assessment of the thoracic aorta. With validation, it may enable the development of an individualized approach to diagnosis and management of aortic disease beyond traditional guidelines.

See Editorial page 6.
For many years, treatment guidelines and intervention criteria have concentrated on traditional echocardiographic measurements for the aortic valve (AV). ${ }^{1,2}$ Furthermore, size remains

\footnotetext{
From the a Department of Cardiothoracic Surgery \& Cardiology, St. George's Hospital, St. George's University of London, London, United Kingdom; ${ }^{\mathrm{b}}$ Department of Biomedical Engineering, King's College London, United Kingdom; and ${ }^{\mathrm{c} D e p a r t-}$ ments of Surgery and Biomedical Engineering, University of Michigan, Ann Arbor, Mich.

This work was supported by the European Research Council under the European Union's Seventh Framework Programme FP/2007-2013/European Research Council (Grant Agreement no. 307532 to A.F.), British Heart Foundation New Horizons program (NH/11/5/29058 to A.F.), the Royal College of Surgeons of England Research Fellowship (to P.Y.), and the United Kingdom Department of Health via the National Institute for Health Research (NIHR) comprehensive Biomedical
}

the principal decision-making index for treatment of the thoracic aorta ${ }^{3,4}$; however, there is growing evidence that hemodynamics play an important role in aneurysm
Research Centre award to Guy's \& St Thomas' NHS Foundation Trust in partnership with King's College London and King's College Hospital NHS Foundation Trust.

Received for publication Feb 12, 2016; revisions received Aug 24, 2016; accepted for publication Sept 14, 2016; available ahead of print Nov 12, 2016.

Address for reprints: Marjan Jahangiri, FRCS(CTh), Department of Cardiothoracic Surgery, St. George's Hospital, Blackshaw Rd, London SW17 0QT, United Kingdom (E-mail: marjan.jahangiri@stgeorges.nhs.uk). $0022-5223 / \$ 36.00$

Copyright (C) 2016 by The American Association for Thoracic Surgery http://dx.doi.org/10.1016/j.jtcvs.2016.09.040 


$\begin{array}{ll}\text { Abbreviations and Acronyms } \\ \text { AR } & =\text { aortic regurgitation } \\ \text { AS } & \text { = aortic stenosis } \\ \text { AV } & \text { = aortic valve } \\ \text { BAV } & \text { = bicuspid aortic valve } \\ \text { CFD } & =\text { computational fluid dynamics } \\ \text { Flow }{ }_{\text {asymmetry }} & =\text { flow asymmetry } \\ \text { HFI } & =\text { helical flow index } \\ \text { MRA } & =\text { magnetic resonance angiography } \\ \text { MRI } & =\text { magnetic resonance imaging } \\ \text { MWSS } & =\text { mean wall shear stress } \\ \text { MWSS Asc Aorta } & =\text { mean wall shear stress averaged } \\ & \text { over the ascending aorta } \\ \text { OSI } & =\text { oscillatory shear index } \\ \text { RL } & =\text { right-left cusp fusion } \\ \text { RN } & =\text { right-non cusp fusion } \\ \text { 3D } & =3 \text { dimensional } \\ \text { TAV } & =\text { tricuspid aortic valve } \\ \text { 2D } & =2 \text { dimensional } \\ \text { WSS } & =\text { wall shear stress }\end{array}$

Scanning this QR code will take you to the appendices and video for this article.

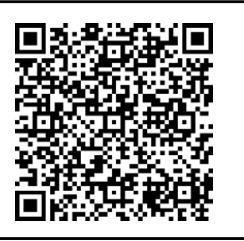

formation, with effects on endothelial homeostasis, smooth muscle response, and fibroblast function. ${ }^{5,6}$

Flow characteristics are highly variable in the thoracic aorta, where the inflow velocity profile is largely dependent on the morphology of the AV. Bicuspid aortic valve (BAV) is the most common congenital cardiac abnormality, with an estimated prevalence of $1 \%$ to $2 \%$, as well as a morbidity and mortality accounting for more than that of all other congenital cardiac diseases combined. ${ }^{7} \mathrm{BAV}$ is often associated with aneurysms of the ascending aorta or aortic root. This dilatation can lead to eventual dissection or rupture. ${ }^{8}$

Disease processes such as aneurysm formation and atherosclerosis are affected greatly by hemodynamic factors in the vascular system. ${ }^{9-12}$ Spatial velocity gradients together with blood viscosity result in wall shear stresses (WSS) on the endothelium. WSS refers to the force per unit area exerted by a moving fluid in the direction of the local tangent of the luminal surface. ${ }^{13}$ Lower WSS has been observed in those carotid arteries with greater levels of plaque formation. ${ }^{14}$ In contrast, high WSS has been associated with aneurysm formation in the cerebral arteries. ${ }^{15}$

Oscillatory shear index (OSI) is a metric that quantifies the changes in direction and magnitude of WSS and has been associated with vasculopathy. ${ }^{16}$ It ranges between 0 (in unidirectional steady flow) and 0.5 (perfectly oscillating back-and-forth velocities over the cardiac cycle). Flow in the thoracic aorta has a significant helical component resulting from a combination of factors such as ventricular twist and torsion, ${ }^{17}$ mechanics of the AV and aortic root, and the curved morphology of the aortic arch. ${ }^{18}$ This helical flow has been related to both plaque deposition ${ }^{19}$ and aneurysm formation. ${ }^{20}$ These hemodynamic and biomechanical parameters can be measured noninvasively by the use of computational fluid dynamics (CFD). In this study, we aimed to use patient-specific CFD to assess the effect of different AV morphologies on velocity profiles, flow patterns and helicity, WSS, and OSI in the thoracic aorta.

\section{METHODS \\ Study Population}

A total of 45 subjects were studied. They were divided into the following 5 groups: volunteers (healthy volunteers with tricuspid aortic valves [TAV]; $\mathrm{n}=5$ ); AR-TAV (aortic regurgitation tricuspid aortic valves; $\mathrm{n}=10$ ); ASTAV (aortic stenosis tricuspid aortic valves; $\mathrm{n}=10$ ); AS-BAV(RL) (aortic stenosis bicuspid aortic valves with fusion of right and left coronary cusps; $\mathrm{n}=10$ ); AS-BAV(RN) (aortic stenosis bicuspid aortic valves with fusion of right and noncoronary cusps; $\mathrm{n}=10$ ). Diagnosis of AS or AR was based on transthoracic echocardiographic data. AS was defined as aortic maximal velocity $>4 \mathrm{~m} / \mathrm{s}$, mean pressure gradient $>40 \mathrm{~mm} \mathrm{Hg}, \mathrm{AV}$ area $<1.0 \mathrm{~cm}^{2}$, or AV area index $<0.6 \mathrm{~cm}^{2} / \mathrm{m}^{2}$. AR was defined as jet width $>65 \%$ of left ventricular outflow tract, vena contracta $\geq 0.6 \mathrm{~cm}$, regurgitant volume $>60 \mathrm{~mL} /$ beat, or effective regurgitant orifice $\geq 0.3 \mathrm{~cm}^{2}$. ${ }^{1}$ Patients with coarctation were excluded. The study was approved by the local ethical committee (St. George's University of London, equivalent to an institutional review board), and informed consent was obtained from all healthy volunteers and patients.

\section{Imaging}

Patients underwent standard-of-care cardiac magnetic resonance imaging (MRI) and magnetic resonance angiography (MRA) to image the entire thoracic aorta, including the head and neck vessels. Time-resolved, velocity-encoded 2-dimensional (2D) anatomic and through-plane PC-MRI (flow MRI) was performed on a plane orthogonal to the ascending aorta at the sino-tubular junction. Heart rates among subjects ranged between 50 and 95 bpm, during which 30 images were reconstructed. Cine sequences were performed for assessment of valve morphology. Velocity sensitivity was set between 150 and $500 \mathrm{~cm} / \mathrm{s}$ depending on the degree of AS. Average scan times were 20 minutes. Supine bilateral upper blood pressure assessment was performed with a Dinamap system (GE Healthcare, Waukesha, Wis). See Appendix E1 for details of the MRI techniques.

\section{Computational Fluid Dynamics}

Three-dimensional (3D) geometric models of the thoracic aorta were reconstructed from the MRA data via the use of custom software (http://www.crimson.software/). ${ }^{21}$ A tetrahedral mesh was created by discretizing the geometric model of the aorta to produce anisotropic meshes consisting of approximately 2.5 to 5.5 million elements. Blood flow simulations were carried out with a stabilized finite element formulation to solve equations enforcing conservation of mass (continuity) and balance of linear momentum (Navier-Stokes) for the flow of an incompressible Newtonian fluid with density $\rho=1.06 \mathrm{~g} / \mathrm{cm}^{3}$ and dynamic viscosity $\mu=0.04$ Poise. ${ }^{22}$ The validated in-house code CRIMSON was used for this process (http://www.crimson.software/). ${ }^{21}$ 


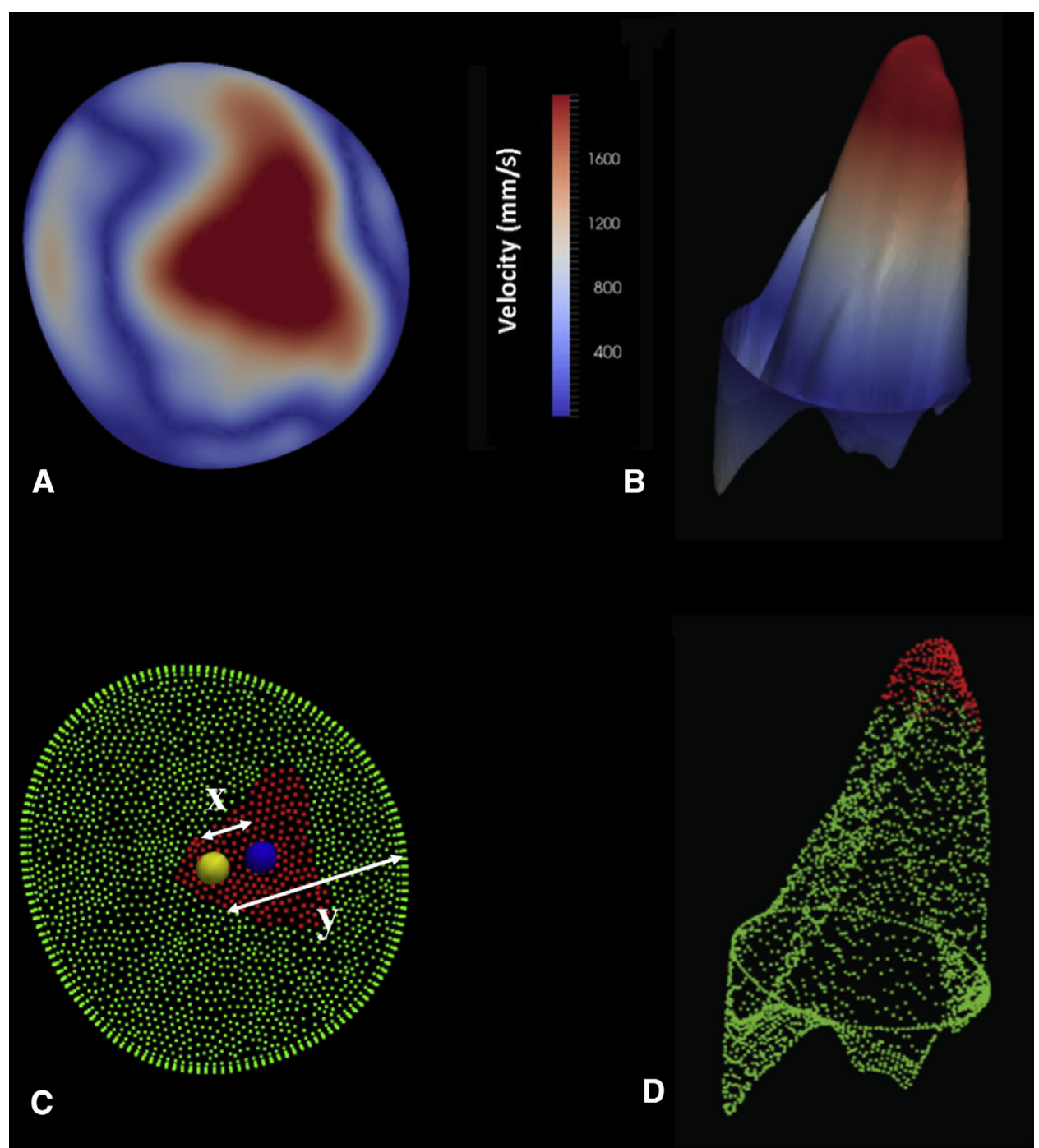

FIGURE 1. A, 2D velocity map above the AV showing areas of different velocity represented by color. B, 3D velocity profile showing a warped geometric representation of the velocity pattern. $\mathrm{C}$ and $\mathrm{D}$, Velocity map and velocity profile showing Vmax ${ }^{15 \%}$ in red dots. The yellow sphere is the centroid of the whole plane, whereas the blue sphere is the centroid of $\operatorname{Vmax}^{15 \%}$. Flow asymmetry is calculated by dividing distance $x$ by distance $y$ as a percentage.

The flow-MRI data were used to define the patient-specific inflow velocity profile. In-house software written in Matlab (The Mathworks Inc, Natick, Mass) was used to extract velocity profiles from the flowMRI and map them to the inlet face of the aortic model.

The outflow boundary conditions were carried out in a patient-specific manner with the use of blood pressure recordings and cardiac output measurements from the flow-MRI data. A coupled-multidomain formulation was used whereby 3 -element Windkessel models (comprising proximal resistance, compliance, and a distal resistance) were coupled to each outflow branch (eg, innominate artery, left common carotid artery, left subclavian artery, and descending aorta) (Appendix E2). ${ }^{23}$

\section{Quantification of Hemodynamic Indices}

Velocity maps (2D) and velocity profiles (3D) were extracted from the PCMRI data above the AV (Figure 1). Flow asymmetry (Flow asymmetry $_{\text {) was }}$ acquired by measuring the distance between the centroid of the top $15 \%$ of peak systolic velocities and the geometric centroid of the inlet plane, as a percentage of the equivalent radius of the inlet plane. A Flow asymmetry $_{\text {of }} 0 \%$ means flow is central to the axis of the vessel, and a Flowasymmetry of $100 \%$ means flow is completely eccentric and at the periphery of the lumen (Figure 1).

Aortic 3D velocity streamlines were calculated from temporally resolved 3D velocity data for the entire thoracic aorta and color coded by blood velocity magnitude. Helicity is a metric that represents the extent to which corkscrew-like motion occurs and is governed by velocity and vorticity. Helical flow index (HFI) was calculated to quantitatively measure the degree of helicity according to Hardman and colleagues. ${ }^{16}$

WSS and OSI were obtained for the entire thoracic aorta, with further in-depth subanalysis in the ascending aorta. To look for asymmetry and differences in WSS and OSI on different sides of the aorta, the ascending aorta was divided into 8 anatomical sectors (anterior, right-anterior, right, rightposterior, posterior, left-posterior, left, and left-anterior sectors; Figure 2).

The results were visualized with the open-source software ParaView (Kitware, Inc, Clifton Park, NY). Further details on how HFI, WSS, and OSI were calculated are included in Appendix E3. 


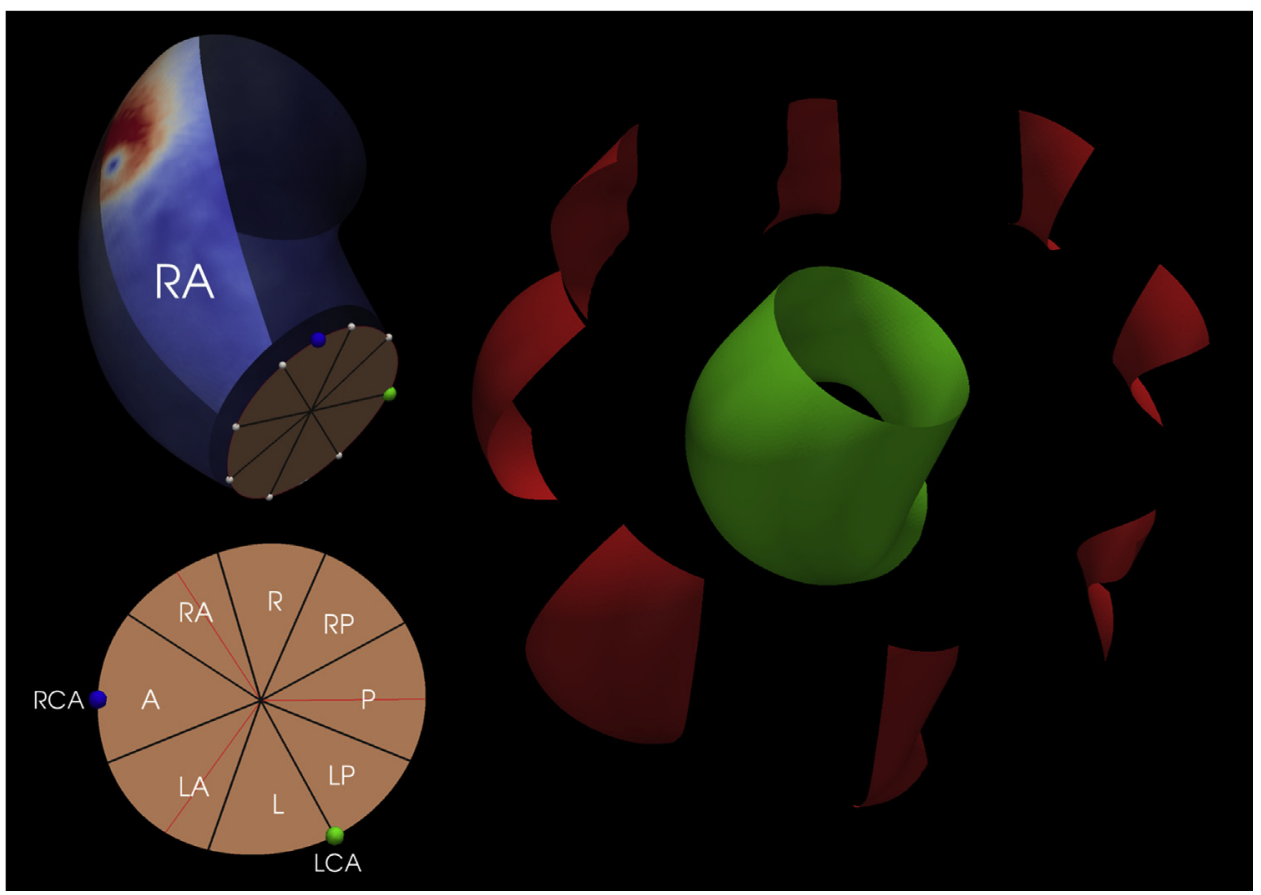

FIGURE 2. The ascending aorta is divided into 8 anatomical segments for subanalysis of hemodynamic parameters. $R A$, Right-anterior; $R$, right; $R P$, rightposterior; $P$, posterior; $L P$, left-posterior; $L$, left; $L A$, left-anterior; $A$, anterior; $R C A$, right coronary artery; $L C A$, left coronary artery.

\section{Statistical Analysis}

Data is presented as mean \pm standard deviation. For each group, data were tested for Gaussian distribution via the Shapiro-Wilk test. One-way analysis of variance was used to test for difference in results between groups. If this revealed $P<.05$, multiple comparisons were carried out between all groups by the use of independent-sample $t$ tests. A $P$ value $<.01$ was considered significant following Bonferroni correction to adjust for multiple comparisons. All statistical analysis was carried out with SPSS (version 21; IBM Corp, Armonk, NY).

\section{RESULTS}

\section{Patient Demographics}

The degree of AS or AR met the severity criteria described previously in all patients except for the volunteer

TABLE 1. Demographics, aortic dimensions, and hemodynamic indices in the 5 study groups

\begin{tabular}{|c|c|c|c|c|c|}
\hline & Volunteers & AR-TAV & AS-TAV & AS-BAV(RL) & AS-BAV $(\mathbf{R N})$ \\
\hline \multicolumn{6}{|l|}{ Demographics } \\
\hline $\mathrm{n}$ & 5 & 10 & 10 & 10 & 10 \\
\hline Male, n (\%) & $5(100)$ & $4(40)$ & $2(20)$ & $3(30)$ & $8(80)$ \\
\hline Age, y & $31.3 \pm 3.1$ & $54.0 \pm 10.8$ & $78.0 \pm 1.4^{*}$ & $63.5 \pm 7.5^{*}$ & $64.0 \pm 8.6$ \\
\hline Hypertension & $1(20)$ & $3(30)$ & $5(50)$ & $4(40)$ & $4(40)$ \\
\hline Beta-blockers & $1(20)$ & $2(20)$ & $4(40)$ & $3(30)$ & $3(30)$ \\
\hline ACEi/ARBs & $1(20)$ & $2(20)$ & $5(50)$ & $3(30)$ & $4(40)$ \\
\hline \multicolumn{6}{|l|}{ Aortic dimensions, $\mathrm{mm}$} \\
\hline SOV diameter & $28.8 \pm 1.3$ & $33.9 \pm 1.9$ & $34.4 \pm 2.8$ & $32.2 \pm 2.4$ & $35.6 \pm 5.1$ \\
\hline STJ diameter & $22.8 \pm 0.9$ & $29.7 \pm 1.6$ & $26.3 \pm 2.2$ & $29.9 \pm 2.7$ & $31.8 \pm 2.0$ \\
\hline MAA diameter & $23.5 \pm 1.0$ & $32.4 \pm 2.4$ & $32.0 \pm 4.3$ & $37.2 \pm 4.4^{*}$ & $39.9 \pm 2.4^{*}$ \\
\hline \multicolumn{6}{|l|}{ Hemodynamic indices } \\
\hline Flow $_{\text {asymmetry }}(\%)$ & $4.7 \pm 2.1$ & $23.2 \pm 5.3$ & $41.1 \pm 9.8$ & $72.6 \pm 17.2$ & $78.9 \pm 6.5 \dagger$ \\
\hline $\mathrm{HFI}_{\text {systole }}$ & $0.24 \pm 0.02$ & $0.28 \pm 0.06$ & $0.26 \pm 0.04$ & $0.39 \pm 0.04 *$ & $0.28 \pm 0.03$ \\
\hline MWSS ${ }^{\text {Asc Aorta }}$, dyn $/ \mathrm{cm}^{2}$ & $9.8 \pm 5.4$ & $17.4 \pm 8.8$ & $35.0 \pm 20.1$ & $27.3 \pm 10.0$ & $37.1 \pm 4.0^{*}$ \\
\hline OSI ${ }^{\text {Asc Aorta }}$ & $0.18 \pm 0.04$ & $0.21 \pm 0.04$ & $0.19 \pm 0.02$ & $0.18 \pm 0.03$ & $0.13 \pm 0.02$ \\
\hline
\end{tabular}

All continuous data are given as mean \pm standard deviation. $A R-T A V$, Aortic regurgitation tricuspid aortic valve; $A S-T A V$, aortic stenosis tricuspid aortic valve; $A S$ - $B A V(R L)$, aortic stenosis bicuspid aortic valve with right left cusp fusion; $A S-B A V(R N)$, aortic stenosis bicuspid aortic valve right-non cusp fusion; $A C E i$, angiotensin-converting enzyme inhibitor; $A R B S$, angiotensin II receptor blockers; SOV, sinuses of Valsalva; STJ, sinotubular junction; $M A A$, mid-ascending aorta; $H F I$, helical flow index; $M W S S^{A s c}$ Aorta, ascending aorta mean wall shear stress; $O S I^{A s c}$ Aorta , ascending aorta oscillatory shear index. *Denotes significant difference after analysis of variance and independent-sample $t$ test $(P<.01)$ between the marked group and volunteer group. ¡ंDenotes significant difference between the marked group and volunteer group, AS-TAV and AR-TAV. 


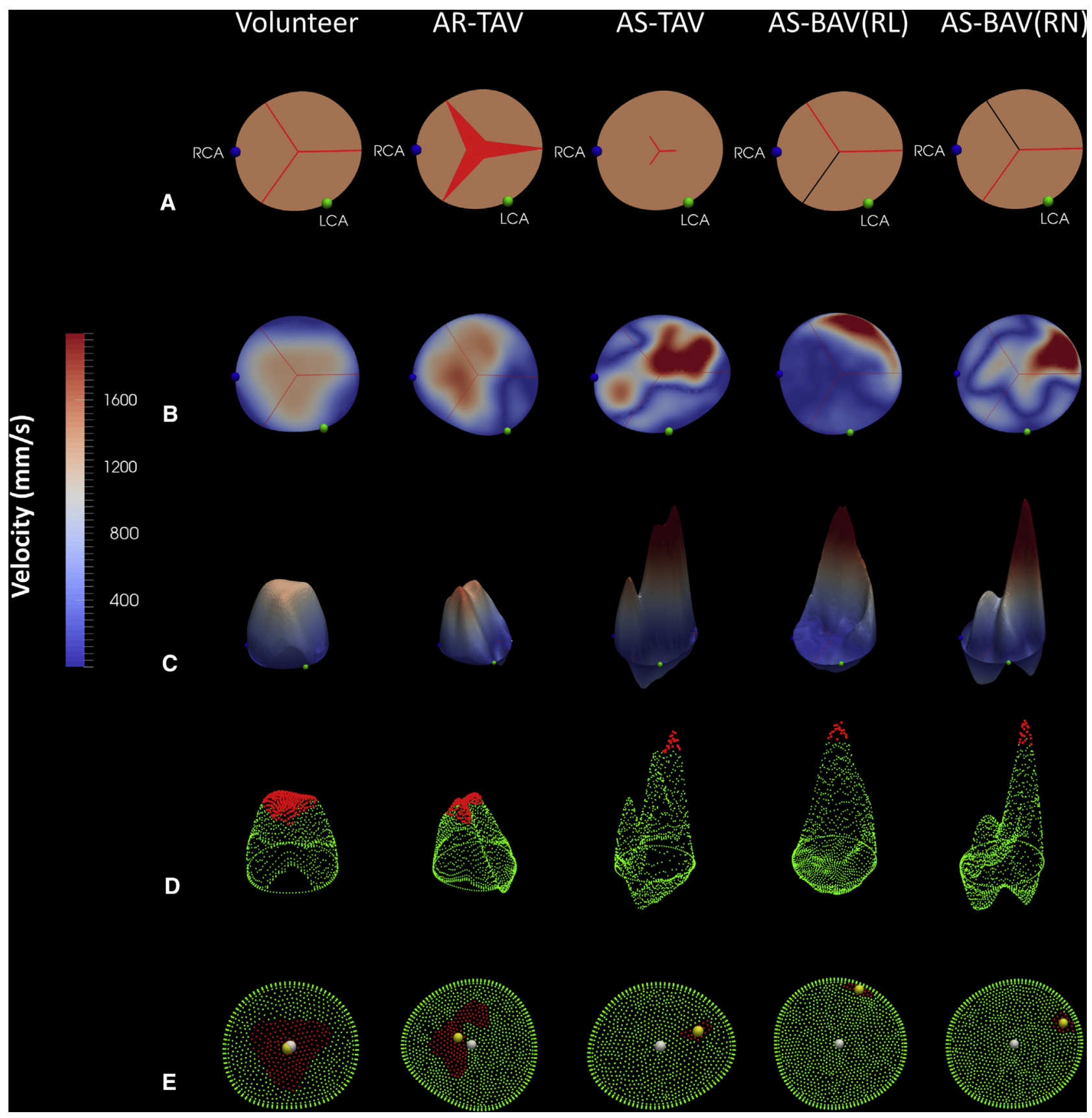

FIGURE 3. A, Schematic diagram of AV morphology in the 5 study groups. B, 2D velocity maps above the AV at peak systole. C, $3 \mathrm{D}$ velocity profiles above the AV at peak systole. D, 3D schematic of the location of $\mathrm{Vmax}{ }^{15 \%}$, as shown in red. E, 2D map of the location of $\mathrm{Vmax}{ }^{15 \%}$ (white circle $=$ centroid of inflow, yellow circle $=$ centroid of $\left.\operatorname{Vmax}^{15 \%}\right)$. AR-TAV, Aortic regurgitation tricuspid aortic valve; $A S$-TAV, aortic stenosis tricuspid aortic valve; $A S$ $B A V(R L)$, aortic stenosis bicuspid aortic valve with right left cusp fusion; $A S-B A V(R N)$, aortic stenosis bicuspid aortic valve right-non cusp fusion; $R C A$, right coronary artery; $L C A$, left coronary artery.

group, who were chosen because of their normalfunctioning AVs. The demographics and aortic dimensions for the 5 groups are displayed in Table 1. Both BAV groups had larger mid-ascending aortic diameters compared with volunteers $(P<.01)$.

\section{Velocity Patterns}

Figure 3 depicts 2D velocity maps and 3D velocity profiles above the AV for a representative subject from each of the 5 groups. When AS is present, the 3D velocity profiles are very peaked and narrow compared with the broader 


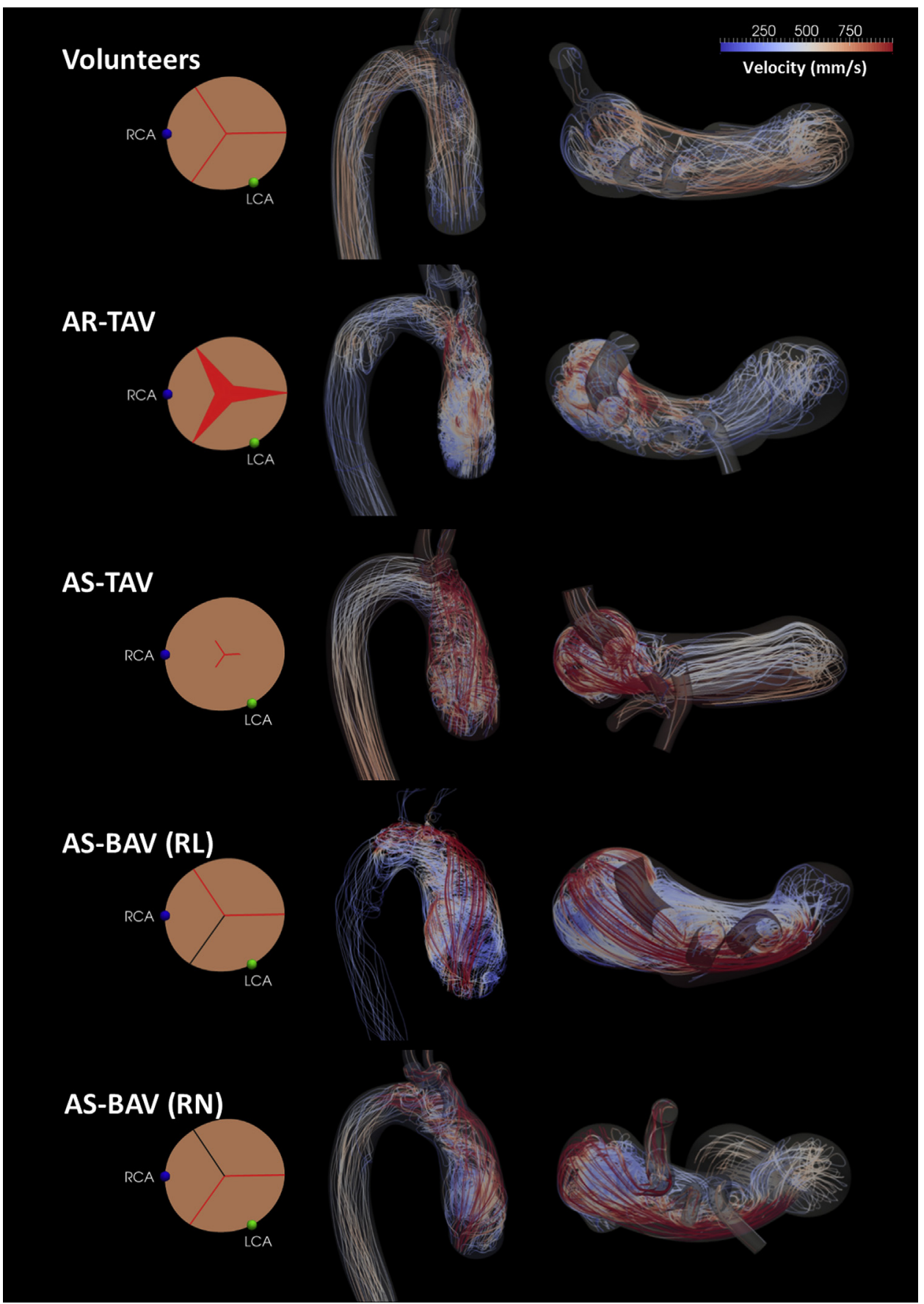

FIGURE 4. 3D velocity streamlines showing trajectory of velocity during peak systole for example patients from the 5 study groups. Greater velocity jets are represented by red. $R C A$, Right coronary artery; $L C A$, left coronary artery; $A R-T A V$, aortic regurgitation tricuspid aortic valve; $A S-T A V$, aortic stenosis tricuspid aortic valve; $A S-B A V(R L)$, aortic stenosis bicuspid aortic valve with right left cusp fusion; $A S-B A V(R N)$, aortic stenosis bicuspid aortic valve right-non cusp fusion.

velocity profiles of the volunteer and AR-TAV groups. Patients with BAV showed high velocity in the periphery of the lumen, whereas patients with TAV displayed more central velocity jets. Patients with BAV had Flow asymmetry almost twice the magnitude of the patients with TAV, indicating blood flow was much more eccentric and asymmetrical (Table 1).

\section{Helicity}

The volunteer group showed laminar flow patterns with relatively uniform parallel $3 \mathrm{D}$ velocity streamlines indicating undisrupted flow (Figure 4). The AS-TAV and AR-TAV groups showed a slightly greater degree of helical flow compared with the volunteer group. Patients with BAV displayed the greatest degree of corkscrew-like helical flow 

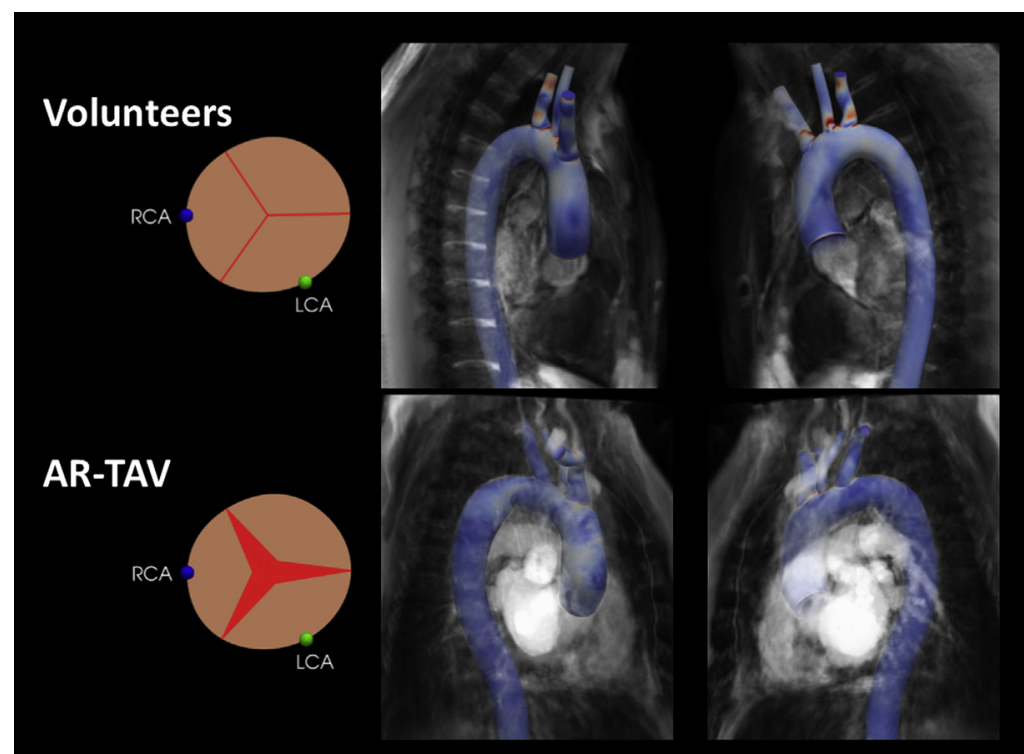

\section{AR-TAV}

RCA
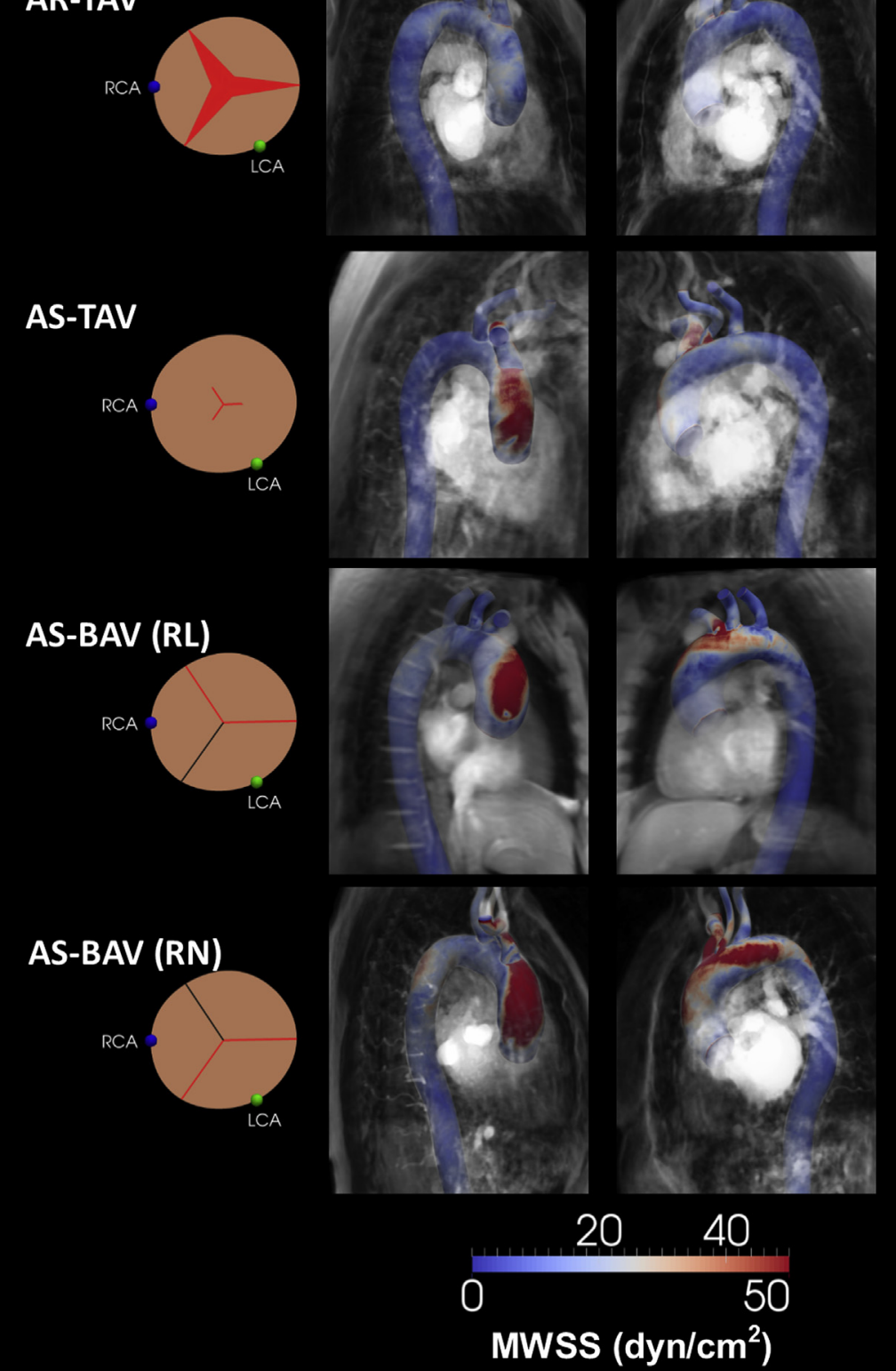

FIGURE 5. MWSS maps for example patients from the 5 study groups. The MWSS maps look at the thoracic aorta from 2 different views. Red represents areas of high WSS. RCA, Right coronary artery; $L C A$, left coronary artery; $A R-T A V$, aortic regurgitation tricuspid aortic valve; $A S-T A V$, aortic stenosis tricuspid aortic valve; $A S-B A V(R L)$, aortic stenosis bicuspid aortic valve with right left cusp fusion; $A S-B A V(R N)$, aortic stenosis bicuspid aortic valve right-non cusp fusion. 


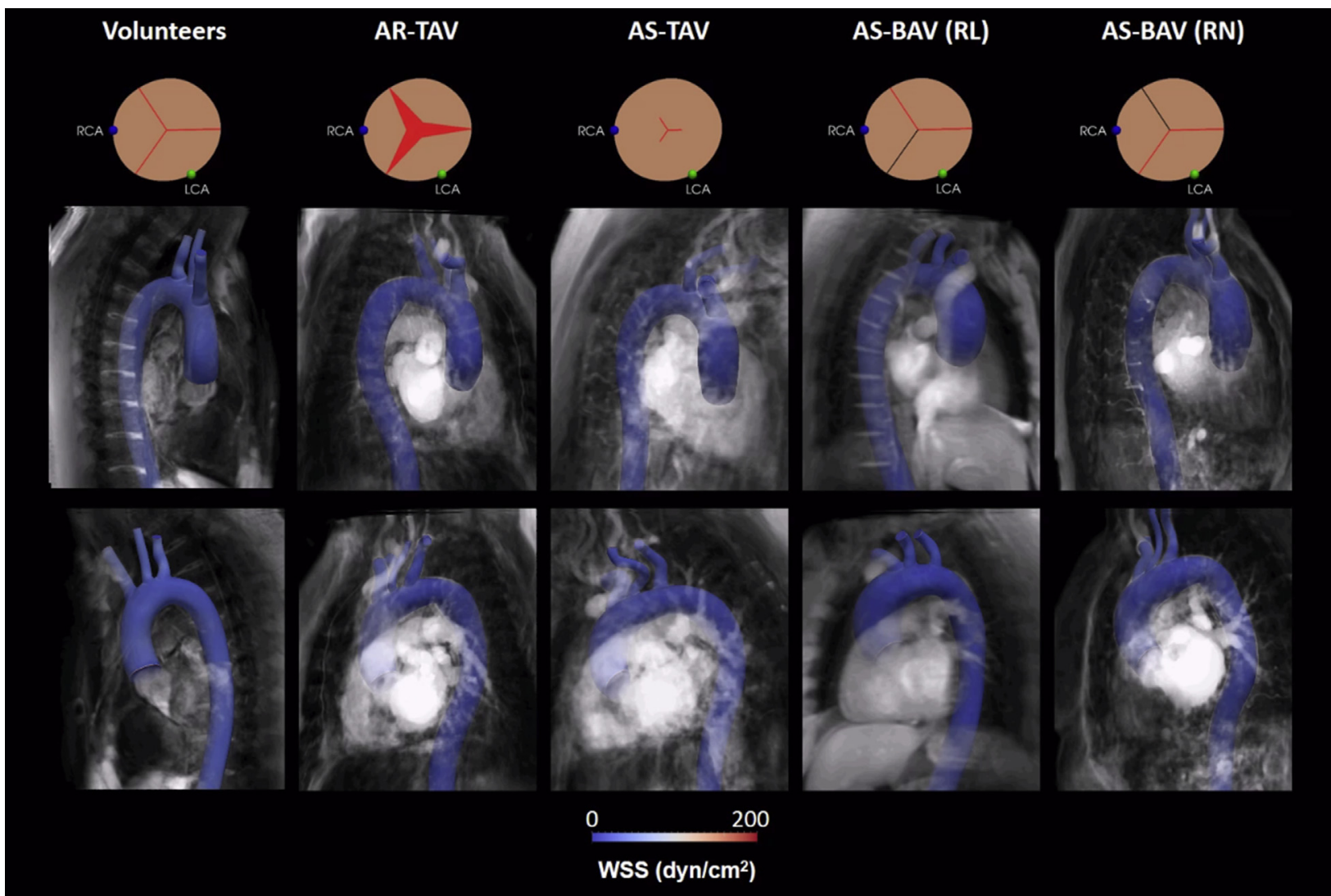

VIDEO 1. WSS maps throughout the cardiac cycle, for example, patients from the 5 study groups. The WSS maps look at the thoracic aorta from 2 different views. Red represents areas of high WSS. AR-TAV, Aortic regurgitation tricuspid aortic valve; $A S-T A V$, aortic stenosis tricuspid aortic valve; $A S-B A V(R L)$, aortic stenosis bicuspid aortic valve with right left cusp fusion; $A S-B A V(R N)$, aortic stenosis bicuspid aortic valve right-non cusp fusion; $R C A$, right coronary artery; LCA, left coronary artery; WSS, wall shear stress. Video available at: http://www.jtcvsonline.org/article/S0022-5223(16)31158-8/addons.

and high-velocity jets traveling in a spiral manner around the ascending aorta and arch. Helicity of blood flow in the ascending aorta was assessed by the HFI, which at peak systole was significantly greater in the AS-BAV(RL) group (Table 1).

\section{Wall Shear Stress}

Figure 5 shows cycle-averaged, or mean wall shear stress (MWSS) maps throughout the thoracic aorta for each of the 5 groups. The 3 groups with AS showed high levels of MWSS in the ascending aorta, predominantly affecting the greater curvature. The volunteer and AR-TAV groups showed lower levels of MWSS. Table 1 shows the values of mean wall shear stress averaged over the ascending aorta $\left(\right.$ MWSS $\left.^{\text {Asc Aorta }}\right)$. MWSS ${ }^{\text {Asc Aorta }}$ was similar in the volunteer and AR-TAV groups. AS-BAV(RN) showed the greatest MWSS ${ }^{\text {Asc Aorta }}$ at $37.1 \pm 4.0 \mathrm{dyn} / \mathrm{cm}^{2}$. Video 1 shows the changing WSS patterns in the aorta throughout the different phases of the cardiac cycle.

For each subject, the ascending aorta was divided into 8 sectors circumferentially. WSS averaged for each sector at each time point was plotted against time over the cardiac cycle (Figure 6). For the volunteer and AR-TAV groups, WSS plots were low in magnitude and the curves remained close together throughout the cardiac cycle, indicating relatively symmetrical and uniform WSS distribution around the ascending aorta. In contrast, the 3 AS groups (AS-BAV[RL], AS-BAV[RN], and ASTAV) showed greater WSS plots in the first one third of the cardiac cycle (corresponding to systole). The sectors displaying high WSS are the right-anterior and right sectors for the patients with $\mathrm{BAV}$, and the anterior, rightanterior, and right sectors for the patients with AS-TAV. This finding indicates significantly asymmetrical WSS distribution.

The 3D radar plots shown in Figure 7 reveal an asymmetrical distribution of MWSS around the circumference of the ascending aorta in the 3 AS groups. When we compared between groups, MWSS in the anterior, right-anterior, and right sectors for AS-BAV(RN) was statistically greater compared with the volunteer and AR-TAV groups $(P<.01)$. MWSS in the right-anterior sector for AS$\mathrm{BAV}(\mathrm{RL})$ is greater compared with the volunteer group (but only achieving $P<.05$ ). 


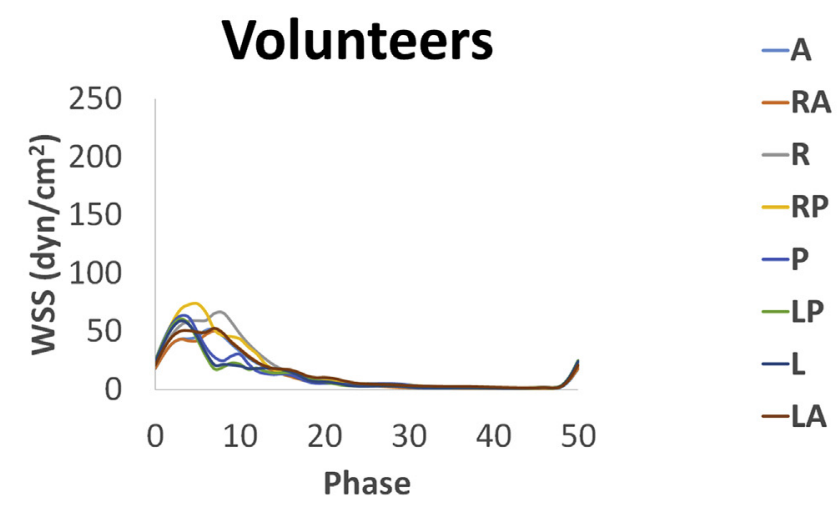

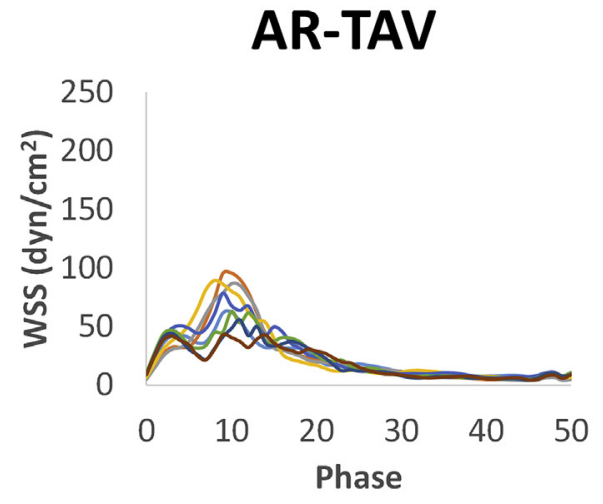

AS-BAV(RL)

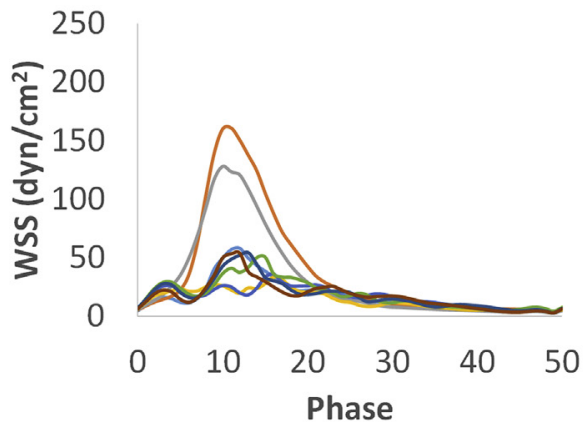

AS-TAV

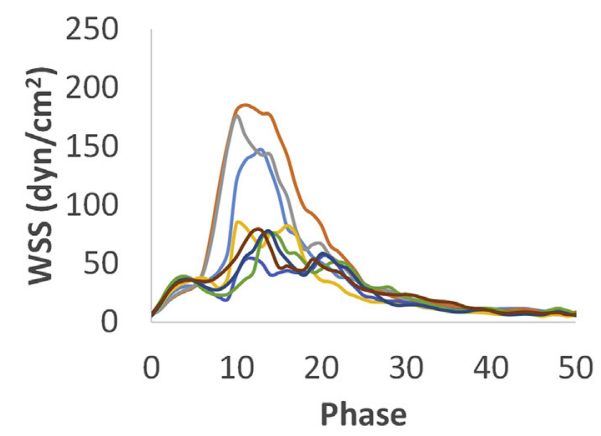

AS-BAV(RN)

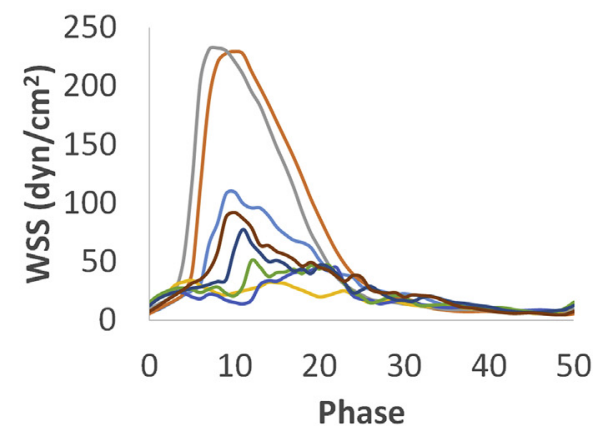

FIGURE 6. WSS plots throughout the cardiac cycle for example patients from each of the 5 groups. Each line represents 1 of the 8 anatomical sectors of the ascending aorta. $A$, Anterior; $R A$, right-anterior; $R$, right; $R P$, right-posterior; $P$, posterior; $L P$, left-posterior; $L$, left; $L A$, left-anterior; $A R$ - $T A V$, aortic regurgitation tricuspid aortic valve; $A S$-TAV, aortic stenosis tricuspid aortic valve; $A S-B A V(R L)$, aortic stenosis bicuspid aortic valve with right left cusp fusion; $A S$ $B A V(R N)$, aortic stenosis bicuspid aortic valve right-non cusp fusion.

\section{Oscillatory Shear Index}

Ascending aorta oscillatory shear index (OSI ${ }^{\text {Asc Aorta }}$ ) was lower in AS-BAV(RN) $\left(\mathrm{OSI}^{\mathrm{Asc} \text { Aorta }}=0.13 \pm 0.02\right.$, compared with $0.18 \pm 0.03$ for AS-BAV[RL], $0.19 \pm 0.02$ for AS-TAV, $0.21 \pm 0.04$ for AR-TAV, and $0.18 \pm 0.04$ for volunteers). Only the volunteer group showed symmetrical OSI values in the ascending aorta. Both bicuspid groups showed relatively lower OSI levels in the right-anterior sectors. For AS-BAV(RN), this finding was statistically significant for the anterior, right-anterior, and right sectors compared with the volunteer group
$(P<.01)$. The tricuspid patient groups (AS-TAV and ARTAV) had greater OSI levels on the left side of the aorta, with a significantly greater OSI in the left-anterior sector for AS-TAV compared with AS-BAV(RN) $(P<.01)$ (Figure 7).

\section{DISCUSSION}

The results from this study show that the presence of BAV was associated with eccentric blood flow patterns and high helicity. AS, whether bicuspid or tricuspid, led to greater WSS levels in the ascending aorta, with the WSS 

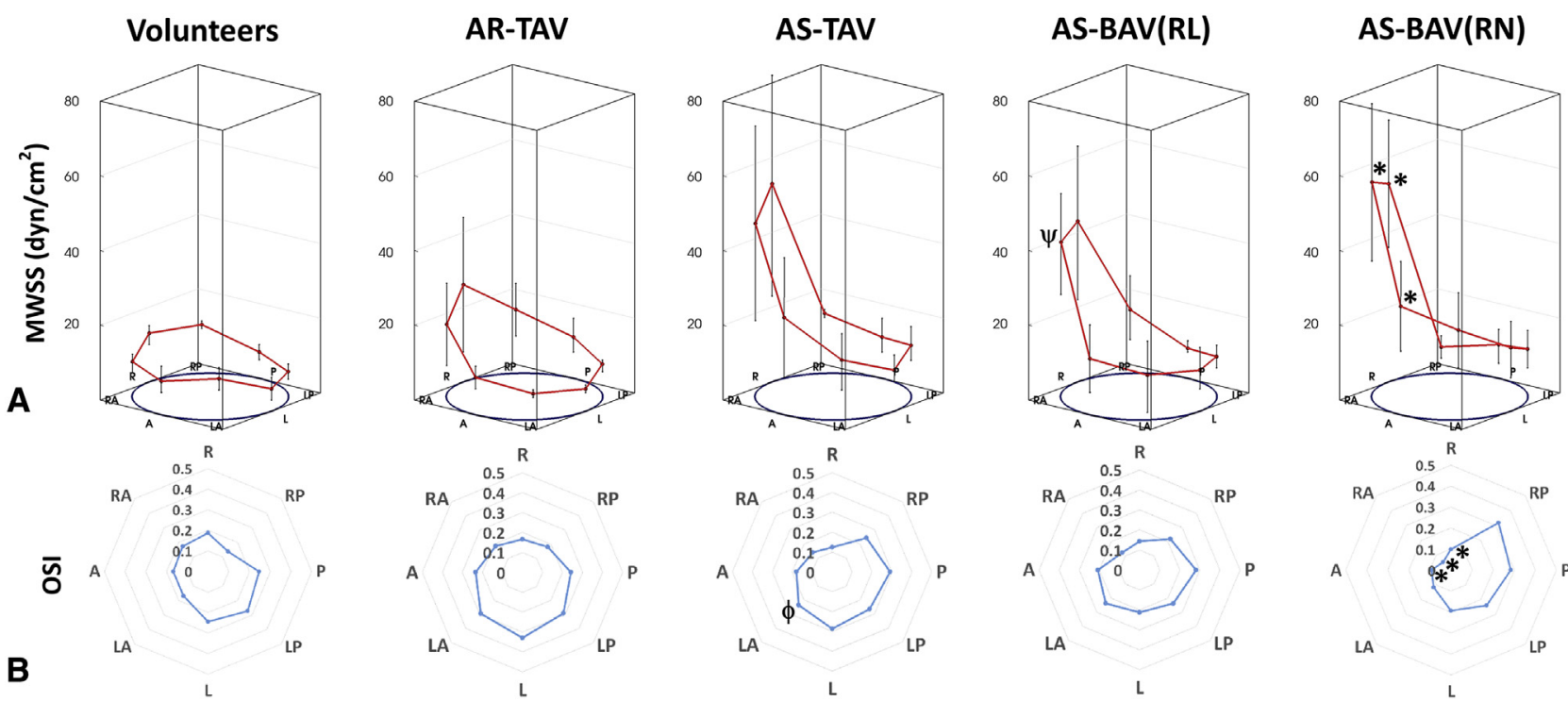

FIGURE 7. A, Plots of MWSS for each of the 8 sectors of the ascending aorta. Error bars represent standard deviations of MWSS. B, Radial graphs of OSI for each of the 8 sectors of the ascending aorta. *Indicates statistically significant differences for AS-BAV(RN) cohorts in comparison with AR-TAV and ARTAV $(P<.01) . \phi$ represents statistically significant differences for AS-TAV cohorts in comparison with AS-BAV(RN) $(P<.01) . \psi$ represents differences for AS-BAV $(\mathrm{RL})$ cohorts in comparison with AR-TAV $(P<.05)$. MWSS, Mean wall shear stress; AR-TAV, aortic regurgitation tricuspid aortic valve; AS-TAV, aortic stenosis tricuspid aortic valve; $A S-B A V(R L)$, aortic stenosis bicuspid aortic valve with right left cusp fusion; $A S-B A V(R N)$, aortic stenosis bicuspid aortic valve right-non cusp fusion; $O S I$, oscillatory shear index; $R A$, right-anterior; $R$, right; $A$, anterior; $R P$, right-posterior; $L A$, left-anterior; $P$, posterior; $L$, left; $L P$, left-posterior.

distribution being asymmetrical and greatest in AS$\mathrm{BAV}(\mathrm{RN})$. OSI also was distributed asymmetrically, with the lowest levels found in patients with $\operatorname{AS}-\mathrm{BAV}(\mathrm{RN})$. These findings corresponded with larger mid-ascending aorta diameters in patients with BAV.

\section{Implications for Management Guidelines}

The results of this study question whether a patientspecific functional assessment of the thoracic aorta should be undertaken instead of size measurements alone. Guidelines of intervention on the aorta consist of maximal aortic diameter as the principal management criteria, with treatment recommended at smaller diameters in the presence of risk factors such as connective tissue disorders or family history of dissection. ${ }^{3}$ These criteria have remained largely unchanged for many years. Despite these guidelines, however, there is still an incidence of rupture or dissection when the aorta is below these size criteria. Elefteriades and colleagues ${ }^{24}$ have shown the yearly risk of rupture, dissection, or death to be $4.4 \%, 4.7 \%, 7.3 \%$, and $12.1 \%$ for aortic sizes $4,5,6$, and $7 \mathrm{~cm}$, respectively, which shows that there remains a small-but-significant incremental risk of aortic events for those patients with aortic size below current intervention criteria.

These findings also provide new insights into sthe adequacy of traditional long-standing indices of valve assessment. Maximum aortic velocity, pressure gradients, valve area, regurgitant volumes, and vena contracta are some of the established echocardiographic indices used to assess AV function. ${ }^{2}$ Although some of these hemodynamic indices relate to symptoms and signs of AV pathology and assess its effect on the left ventricle, they do not help in the assessment of AV-related aortopathy. There is as of yet no robust functional assessment of the effect of the $\mathrm{AV}$ on the aorta, both in terms of flow changes and mechanical stresses. Evidence shows a strong association between BAV and aneurysm of the ascending aorta, with a risk of subsequent dissection or rupture ${ }^{8}$; however, the decision of when to intervene surgically on this group of patients can be difficult. The degree of aortic dilatation can be highly variable, and management guidelines are supported by limited evidence. It is not uncommon to be presented with a patient with BAV who has an intermediate severity of valve dysfunction and a moderate degree of aortic dilatation. This patient may not fulfill current criteria for surgical intervention on the $\mathrm{AV}$ or the aorta; however, assessment of some of the functional indices outlined in this study may help in decision making.

\section{Valve Morphology and Hemodynamics}

WSS was greater in the presence of AS, whether BAV or TAV. MWSS was greatest in the patients with rightnonfusion BAV. The WSS distribution was highly asymmetrical, with the right-anterior and right sectors experiencing the greatest levels of WSS. These sectors correlate with the convexity (greater curvature) of the ascending aorta. It was 
interesting to note that both BAV groups had significantly larger mid-ascending aorta diameters compared with the volunteer group. These trends are in keeping with previous CFD studies, ${ }^{25,26}$ although our results are based on larger patient numbers, less hemodynamic assumptions, and more patient-specific parameters. Four-dimensional (4D) flow MRI studies by Mahadevia and colleagues ${ }^{27}$ also found WSS to be greater in sectors corresponding to the greater curvature of the ascending aorta in patients with BAV. Meierhofer and colleagues ${ }^{28}$ also used 4D flow MRI and measured WSS to be up to $7.5 \mathrm{dyn} / \mathrm{cm}^{2}\left(0.75 \mathrm{~N} / \mathrm{m}^{2}\right)$ in the ascending aorta of patients with healthy tricuspid valves, corresponding to $9.8 \pm 5.4 \mathrm{dyn} / \mathrm{cm}^{2}$ measured in our study. WSS measurements for patients with BAV in their study were greater than patients with TAV but were not as high as the levels seen in our study. This finding may be attributed to the lack of AS or insufficiency in their patients with BAV.

Our results also correlate well with the findings of Della Corte and colleagues, ${ }^{29}$ who found that medial degeneration was more severe in the greater curvature of BAV aortas. Type I and III collagen were reduced in this area. Smooth muscle cell apoptosis was seen to be increased in the greater curvature of BAV aortas even before significant dilatation had occurred. ${ }^{30}$

OSI throughout the ascending aorta was lower in the right-non-BAV group. When we compared the 8 sectors, lower OSI was seen in the anterior, right-anterior, and right sectors. Greater OSI has been associated with increased atherosclerotic plaque formation and an increase in vessel wall thickness. ${ }^{31}$ It may be postulated that this lower OSI seen in AS-BAV $(\mathrm{RN})$ may be protective from atherosclerotic plaques, or perhaps to even cause thinning of the wall. The 3 sectors that demonstrated lower OSI were those corresponding to the greater curvature of the ascending aorta, typically the site of wall thinning. ${ }^{29}$ Further work in this area may lend additional insights into the mechanisms of aortopathy.

As the morphology of the AV changed relative to healthy volunteers, blood flow helicity increased. There was a stepwise increase in helicity from volunteer $\rightarrow$ TAV (AS or AR) $\rightarrow \mathrm{AS}-\mathrm{BAV}(\mathrm{RN}) \rightarrow \mathrm{AS}-\mathrm{BAV}(\mathrm{RL})$. This may be related to the asymmetrical flow seen in patients with BAV. Helicity has been shown to play an important role in plaque deposition ${ }^{19}$ and aneurysm formation. ${ }^{20}$ High helicity has been linked with high WSS, in part due to the nonaxial velocity component as well as its link with disrupted flow. ${ }^{32,33}$ This trend also was seen in our results.

This work focused on hemodynamic indices in the aorta and their correlation to known vasculopathies. Pressure, on the other hand, is the most important contributor to tensile stress, the key determinant in aneurysm rupture when wall stress exceeds wall strength. WSS acts in the direction of the vessel wall and is governed by velocity. It is a smaller quantity compared with tensile stress ${ }^{34}$ and the tensile strength $^{35}$ of the aortic wall (Pascals for WSS compared with hundreds of kiloPascals for tensile stress); however, it interacts with the vessel wall via different mechanisms. Tensile stress could be estimated by finite element modeling of the aorta using appropriate constitutive models to describe the characteristics of the wall.

\section{Future Application of CFD}

Current assessment of patients with aortopathy is largely limited to surveillance of aortic size by computed tomography or MRA. There remains a lack of information regarding each patient's aortic wall biomechanics and flow patterns. Indices such as WSS and OSI have been shown to be associated with aneurysm formation/rupture ${ }^{15}$ and vasculopathy. ${ }^{16}$ This study found WSS to be highest and OSI to be lowest in the greater curvature of the ascending aorta of bicuspid patients, the site of typical dilatation and thinning. ${ }^{29}$ Further investigations should include longitudinal studies to assess the correlation between the proposed hemodynamic indices and aortopathy events, as well as the effect of these indices on proteomic changes, gene expression, and inflammatory changes in the aortic wall. Knowledge of these parameters may then help highlight those patients at greater risk of aortic complications and help guide timing of surgical intervention.

4D flow MRI also can be used to assess some of these hemodynamic parameters; however, because of lower spatial and temporal resolution, underestimation of WSS is a recognized problem. ${ }^{36}$ Furthermore, 4D flow MRI has a longer acquisition time, which may be inconvenient for the patient. The MRA and PC-MRI image acquisition required to carry out CFD is of significantly shorter duration.

CFD is a noninvasive approach to quantify biomechanics and hemodynamics in the assessment of aortic pathology. Future development and incorporation of CFD algorithms and tools into imaging modality systems may give clinicians access to each patient's individual aortic flow dynamics and biomechanics.

\section{Limitations}

The results from this study have not been adjusted for patient characteristics such as age. Future studies should contain different AV morphology groups such as AR-BAV and even mixed AV disease groups (mixed AS and AR). Furthermore, a comparison of BAV morphologies with different degrees of stenosis or regurgitation should be made to assess hemodynamic parameters in bicuspid patients with less than severe AS or AR.

Computations were performed under the assumption of rigid walls. Increasing compliance and elasticity causes a small reduction in WSS, so our results may have overestimated WSS in all 5 groups. As the aorta dilates, its compliance and elasticity reduce, and it becomes stiffer and more rigid. This makes it more susceptible to greater shear 
stresses and increases the risk of rupture or dissection. ${ }^{3}$ The 2 bicuspid groups in this study had significantly larger aortas, and it may be suggested that the aortic wall may have been stiffer than the smaller diameter tricuspid groups. Therefore, WSS would have been proportionally more overestimated in the TAV groups. Thus, the actual differences in WSS between BAV and TAV groups could have been even greater than that seen in this study. In future studies, fluid-structure interaction analysis that takes into account the elasticity of the aortic wall will be performed.

\section{CONCLUSIONS}

The outcomes in aortic hemodynamics from this study may relate to a potential explanation for the increased incidence of aortopathy in patients with BAV and indeed to some degree of poststenotic dilatation seen in some patients with AS-TAV. Our results show that there are increased velocity jets found at the periphery of the aorta in patients with BAV. Velocity streamlines show that these narrow jets impact on the greater curvature of the ascending aorta and subsequently spiral around the ascending aorta and arch. They cause increased WSS and reduced OSI at the greater curvature, corresponding to larger mid-ascending aorta diameters. These findings provide a possible mechanistic link between AV morphology and aortopathy. CFD is a noninvasive, functional assessment of the thoracic aorta and may enable the development of an improved personalized approach to the diagnosis and management of aortic disease beyond traditional guidelines.

\section{Conflict of Interest Statement}

Authors have nothing to disclose with regard to commercial support.

The authors acknowledge support from Desmond DillonMurphy and Dr Christopher Arthurs for their expertise and technical assistance.

\section{References}

1. Nishimura RA, Otto CM, Bonow RO, Carabello BA, Erwin JP III, Guyton RA, et al. 2014 AHA/ACC guideline for the management of patients with valvular heart disease: a report of the American College of Cardiology/American Heart Association Task Force on Practice Guidelines. J Am Coll Cardiol. 2014;63:e57-185.

2. Vahanian A, Alfieri O, Andreotti F, Antunes MJ, Baron-Esquivias G, Baumgartner $\mathrm{H}$, et al. Guidelines on the management of valvular heart disease (version 2012): the Joint Task Force on the Management of Valvular Heart Disease of the European Society of Cardiology (ESC) and the European Association for Cardio-Thoracic Surgery (EACTS). Eur J Cardiothorac Surg. 2012;42: S1-44.

3. Erbel R, Aboyans V, Boileau C, Bossone E, Bartolomeo RD, Eggebrecht H, et al. 2014 ESC Guidelines on the diagnosis and treatment of aortic diseases: document covering acute and chronic aortic diseases of the thoracic and abdominal aorta of the adult. The Task Force for the Diagnosis and Treatment of Aortic Diseases of the European Society of Cardiology (ESC). Eur Heart J. 2014;35: 2873-926.

4. Svensson LG, Adams DH, Bonow RO, Kouchoukos NT, Miller DC, O’Gara PT, et al. Aortic valve and ascending aorta guidelines for management and quality measures. Ann Thorac Surg. 2013;95:S1-66.
5. Gnasso A, Carallo C, Irace C, Spagnuolo V, De Novara G, Mattioli PL, et al. Association between intima-media thickness and wall shear stress in common carotid arteries in healthy male subjects. Circulation. 1996;94:3257-62.

6. Malek AM, Alper SL, Izumo S. Hemodynamic shear stress and its role in atherosclerosis. JAMA. 1999;282:2035-42.

7. Ward C. Clinical significance of the bicuspid aortic valve. Heart. 2000;83:81-5.

8. Della Corte A, Bancone C, Quarto C, Dialetto G, Covino FE, Scardone M, et al. Predictors of ascending aortic dilatation with bicuspid aortic valve: a wide spectrum of disease expression. Eur J Cardiothorac Surg. 2007;31:397-404.

9. Friedman MH, Hutchins GM, Bargeron CB, Deters OJ, Mark FF. Correlation between intimal thickness and fluid shear in human arteries. Atherosclerosis. 1981; 39:425-36.

10. Zarins CK, Giddens DP, Bharadvaj BK, Sottiurai VS, Mabon RF, Glagov S. Carotid bifurcation atherosclerosis. Quantitative correlation of plaque localization with flow velocity profiles and wall shear stress. Circ Res. 1983;53:502-14.

11. Yeung JJ, Kim HJ, Abbruzzese TA, Vignon-Clementel IE, Draney-Blomme MT, Yeung KK, et al. Aortoiliac hemodynamic and morphologic adaptation to chronic spinal cord injury. J Vasc Surg. 2006;44:1254-65.

12. Humphrey JD, Taylor CA. Intracranial and abdominal aortic aneurysms: similarities, differences, and need for a new class of computational models. Annu Rev Biomed Eng. 2008;10:221-46.

13. Efstathopoulos EP, Patatoukas G, Pantos I, Benekos O, Katritsis D, Kelekis NL. Wall shear stress calculation in ascending aorta using phase contrast magnetic resonance imaging. Investigating effective ways to calculate it in clinical practice. Phys Med. 2008;24:175-81.

14. Gnasso A, Irace C, Carallo C, De Franceschi MS, Motti C, Mattioli PL, et al. In vivo association between low wall shear stress and plaque in subjects with asymmetrical carotid atherosclerosis. Stroke. 1997;28:993-8.

15. Cebral JR, Vazquez M, Sforza DM, Houzeaux G, Tateshima S, Scrivano E, et al Analysis of hemodynamics and wall mechanics at sites of cerebral aneurysm rupture. J Neurointerv Surg. 2015;7:530-6.

16. Hardman D, Semple SI, Richards JM, Hoskins PR. Comparison of patientspecific inlet boundary conditions in the numerical modelling of blood flow in abdominal aortic aneurysm disease. Int J Numer Method Biomed Eng. 2013; 29:165-78.

17. Baciewicz FA, Penney DG, Marinelli WA, Marinelli R. Torsional ventricular motion and rotary blood flow. What is the clinical significance. Cardiac Chronicle 1991;5:1-8.

18. Chandran KB. Flow dynamics in the human aorta. J Biomech Eng. 1993;115 611-6.

19. Kilner PJ, Yang GZ, Mohiaddin RH, Firmin DN, Longmore DB. Helical and retrograde secondary flow patterns in the aortic arch studied by threedirectional magnetic resonance velocity mapping. Circulation. 1993;88:2235-47.

20. Hope MD, Hope TA, Crook SE, Ordovas KG, Urbania TH, Alley MT, et al. 4D flow CMR in assessment of valve-related ascending aortic disease. JACC Cardiovasc Imaging. 2011;4:781-7.

21. Figueroa C, Khlebnikov R, Lau KD, Arthurs CJ, Dillon-Murphy D, AlastrueyArimon J, et al. Crimson Software. Available at: http://www.crimson.software. Accessed February 2016

22. Figueroa CA, Vignon-Clementel IE, Jansen KC, Hughes TJ, Taylor CA. A coupled momentum method for modeling blood flow in three-dimensional deformable arteries. Comput Methods Appl Mech Eng. 2006;195: 5685-706.

23. Vignon-Clementel IE, Figueroa CA, Jansen KE, Taylor CA. Outflow boundary conditions for 3D simulations of non-periodic blood flow and pressure fields in deformable arteries. Comput Methods Biomech Biomed Engin. 2010;13:625-40.

24. Elefteriades JA, Ziganshin BA, Rizzo JA, Fang H, Tranquilli M, Paruchuri V, et al. Indications and imaging for aortic surgery: size and other matters. J Thorac Cardiovasc Surg. 2015;149:S10-3.

25. Rinaudo A, Pasta S. Regional variation of wall shear stress in ascending thoracic aortic aneurysms. Proc Inst Mech Eng H. 2014;228:627-38.

26. Viscardi F, Vergara C, Antiga L, Merelli S, Veneziani A, Puppini G, et al Comparative finite element model analysis of ascending aortic flow in bicuspid and tricuspid aortic valve. Artif Organs. 2010;34:1114-20.

27. Mahadevia R, Barker AJ, Schnell S, Entezari P, Kansal P, Fedak PW, et al. Bicuspid aortic cusp fusion morphology alters aortic three-dimensional outflow patterns, wall shear stress, and expression of aortopathy. Circulation. 2014;129:673-82.

28. Meierhofer C, Schneider EP, Lyko C, Hutter A, Martinoff S, Markl M, et al. Wall shear stress and flow patterns in the ascending aorta in patients with bicuspid aortic valves differ significantly from tricuspid aortic valves: a prospective study. Eur Heart J Cardiovasc Imaging. 2013;14:797-804. 
29. Della Corte A, De Santo LS, Montagnani S, Quarto C, Romano G, Amarelli C, et al. Spatial patterns of matrix protein expression in dilated ascending aorta with aortic regurgitation: congenital bicuspid valve versus Marfan's syndrome. J Heart Valve Dis. 2006;15:20-7.

30. Della Corte A, Quarto C, Bancone C, Castaldo C, Di Meglio F, Nurzynska D, et al. Spatiotemporal patterns of smooth muscle cell changes in ascending aortic dilatation with bicuspid and tricuspid aortic valve stenosis: focus on cell-matrix signaling. J Thorac Cardiovasc Surg. 2008;135:8-18.

31. Campbell IC, Ries J, Dhawan SS, Quyyumi AA, Taylor WR, Oshinski JN. Effect of inlet velocity profiles on patient-specific computational fluid dynamics simulations of the carotid bifurcation. J Biomech Eng. 2012;134:051001.

32. Morbiducci U, Ponzini R, Grigioni M, Redaelli A. Helical flow as fluid dynamic signature for atherogenesis risk in aortocoronary bypass. A numeric study. J Biomech. 2007;40:519-34.

33. Frazin LJ, Vonesh MJ, Chandran KB, Shipkowitz T, Yaacoub AS, McPherson DD. Confirmation and initial documentation of thoracic and abdominal aortic helical flow. An ultrasound study. ASAIO J. 1996;42:951-6.
34. Fillinger MF, Marra SP, Raghavan ML, Kennedy FE. Prediction of rupture risk in abdominal aortic aneurysm during observation: wall stress versus diameter. J Vasc Surg. 2003;37:724-32.

35. Ferrara A, Morganti S, Totaro P, Mazzola A, Auricchio F. Human dilated ascending aorta: Mechanical characterization via uniaxial tensile tests. $J$ Mech Behav Biomed Mater. 2016:53:257-71.

36. Barker AJ, Markl M, Burk J, Lorenz R, Bock J, Bauer S, et al. Bicuspid aortic valve is associated with altered wall shear stress in the ascending aorta. Circ Cardiovasc Imaging. 2012;5:457-66.

37. Xiong G, Figueroa CA, Xiao N, Taylor CA. Simulation of blood flow in deformable vessels using subject-specific geometry and spatially varying wall properties. Int J Numer Method Biomed Eng. 2011;27: 1000-16.

Key Words: bicuspid aortic valve, aorta, wall shear stress, MRI

Readers who found these articles interesting may also like to read the following papers found in recent and future issues of our sister publications, Seminars in Thoracic and Cardiovascular Surgery and Operative Techniques in Thoracic and Cardiovascular Surgery!

\section{Acquired: Valvular Heart Disease}

Original Submission: Should Moderate-to-Severe Tricuspid Regurgitation be Repaired During Reoperative Left-Sided Valve Procedures? Igor Gosev. Semin Thoracic Surg 2016; 28:38-45.

Editorial Commentary: To Fix or Not to Fix? That is the Question. Kenton J. Zehr. Semin Thoracic Surg 2016;28:46-47.

Original Submission: Current Hypotheses in Cardiac Surgery: Biofilm in Infective Endocarditis. Haytham Elgharably. Semin Thoracic Surg 2016; 28:56-59.

Editorial Commentary: Treatment of Infective Endocarditis - Are We On the Right Track? Hans-Joachim Schafers. Semin Thoracic Surg 2016; 28:60-61.

Original Submission: Posterior Leaflet Detachment, Augmentation, and Reconstruction for Treatment of Functional Mitral Valve Regurgitation. Rakesh M. Suri. Semin Thoracic Surg 2015; 27:91-94.

Editorial Commentary: Patch Augmentation of Mitral Valve Leaflet in Ischemic Mitral Regurgitation. Tirone E. David. Semin Thoracic Surg 2015; 27:95-96.

Original Submission: Elevated Stroke Risk Associated with Femoral Artery Cannulation During Mitral Valve Surgery. Kareem Bedeir. Semin Thoracic Surg 2015; 27:97-103.

Editorial Commentary: Are We Going Backwards or Forwards in Minimally Invasive Mitral Valve Surgery? Three Eras of Perfusion Strategy. Vinay Badhwar. Semin Thoracic Surg 2015; 27:104-105.

Current Readings: Selection of Valve Prostheses. Cristian Rosu. Semin Thoracic Surg 2015; 27:152-158.

Original Submission: Long-Term Hemodynamic Performance of the Aortic Valve Late After David I: An Echocardiographic Study. Antonino S. Rubino. Semin Thoracic Surg 2015; 27:257-263.

Editorial Commentary: Back to David I. Tirone E. David. Semin Thoracic Surg 2015; 27:264-265.

Discussion in Cardiothoracic Treatment and Care: Aortic Valve/Root Repair. Tirone David. Semin Thoracic E Surg 2015; 27:271287.

Biatrial Transseptal Approach for Combined Mitral Valve and Tricuspid Valve Operations. Mahim Malik. Oper Tech Thorac Cardiovasc Surg 2015; 20:2-16.

Mitral Valve Replacement for Infective Endocarditis with Annular Abscess: Annular Reconstruction. Gregory J. Bittle. Oper Tech Thorac Cardiovasc Surg 2015;20:17-30.

Mitral Annuloplasty Using A Biodegradable Annuloplasty Ring. Sanjay Cherian. Oper Tech Thorac Cardiovasc Surg 2015; 20:124134.

Myxomatous Mitral Valve Repair: Loop Neochord Technique. Robert C. Neely. Oper Tech Thorac Cardiovasc Surg 2015; 20:106-123. 


\section{APPENDIX E1: MAGNETIC RESONANCE IMAGING (MRI) PARAMETERS}

Patients underwent standard-of-care cardiac MRI and magnetic resonance angiography to image the entire thoracic aorta, including the head and neck vessels. Gadolinium $(0.3 \mathrm{~mL} / \mathrm{kg}$; gadodiamide, Omniscan; GE Healthcare, Waukesha, Wis) was infused with a breath-held 3-dimensional fast gradient echo sequence using a Philips Achieva 3T scanner (Philips Medical Systems, Eindhoven, The Netherlands). Acquired slice thickness was 1.0 to $2.0 \mathrm{~mm}$, with 56 to 80 sagittal slices per volume. A $344 \times 344$ acquisition matrix was used with a field of view of $35 \mathrm{~cm} \times 35 \mathrm{~cm}$ (reconstructed to slices with a spatial resolution of $0.49 \mathrm{~mm} \times 0.49 \mathrm{~mm}$ and resampled to a slice thickness of $1.00 \mathrm{~mm}$ ). Other parameters included a repetition time of 3.9 milliseconds, echo time of 1.4 milliseconds, and a flip angle of $27^{\circ}$.

Time-resolved, velocity-encoded 2-dimensional anatomic and through-plane PC-MRI (flow MRI) was performed on a plane orthogonal to the ascending aorta at the sino-tubular junction. Heart rates amongst subjects ranged between 50 and $95 \mathrm{bpm}$, during which 30 images were reconstructed. Imaging parameters included repetition time, echo time, and flip angle of 4.1 to $4.2 \mathrm{~ms}, 2.4$ to $2.5 \mathrm{~ms}$, and $15^{\circ}$, respectively. The field of view was 30 to $35 \mathrm{~cm} \times 30$ to $35 \mathrm{~cm}$ with an acquisition matrix of 152 to $170 \times 120$ to 150 and a slice thickness of $10 \mathrm{~mm}$, resulting in a voxel size of $2.3 \mathrm{~mm} \times 2.4 \mathrm{~mm}$ $\times 10 \mathrm{~mm}$ (resampled at $1.37 \mathrm{~mm} \times 1.36 \mathrm{~mm} \times 10 \mathrm{~mm}$ ). Data acquisition was carried out within a single breath-hold and gated to the cardiac cycle. Cine sequences were performed for assessment of valve morphology. Velocity sensitivity was set between 150 and $500 \mathrm{~cm} / \mathrm{s}$, depending on the degree of aortic stenosis. Average scan times were 20 minutes.

\section{APPENDIX E2: OUTFLOW BOUNDARY CONDITIONS}

Patient-specific outflow boundary conditions were prescribed at each outlet in the innominate artery, left common carotid artery, left subclavian artery, and descending aorta. Upper limb blood pressure was measured after each study with the use of an automated sphygmomanometer cuff with participants in the supine position. A 3-element Windkessel RCR model ${ }^{\mathrm{E} 1, \mathrm{E} 2}$ was superimposed on each outlet. The Windkessel model represents the arterial tree beyond the model outlet in an intuitive and physiological manner comprising a proximal resistance $\left(R_{p}\right)$, compliance $(C)$, and a distal resistance $\left(R_{d}\right)$ for each outlet. Table E1 shows the values of the outflow boundary conditions for an example patient from each group.

$R_{\text {total }}$ is the total resistance in the vascular system. These values were calculated in the following patient-specific manner:

$$
R_{\text {total }}=\frac{P}{Q}
$$

where $P=$ patient's mean arterial pressure, $Q=$ flow, as derived from the PC-MRI inlet velocity profile.

$$
R_{\text {total }}=\left(\sum_{i} \frac{1}{R_{i}}\right)^{-1}
$$

and $R_{i}$ is the total resistance for each individual outlet.

$$
R_{i}=R_{p}+R_{d}
$$

for each individual outlet, where $R_{p}$ is proximal resistance, and $R_{d}$ is the distal resistance. $R_{i}$ is calculated using the following relationship:

$$
\frac{R_{\text {total }}}{R_{i}}=\frac{A_{i}}{A_{T}}
$$

where $A_{i}$ is the cross-sectional area of the individual outlet, and $A_{T}$ is the total cross-sectional area of all outlets in the model. We assumed the ratio of proximal to total resistance:

$$
\frac{R_{p}}{\left(R_{p}+R_{d}\right)}=0.056^{\mathrm{E} 3}
$$

Similarly, $C_{T}$ is the total compliance in the vascular system.

$$
C_{T}=\sum_{i} C_{i}
$$

and

$$
\frac{C_{i}}{C_{T}}=\frac{A_{i}}{A_{T}}
$$

Therefore, the flow and compliance at each outlet is proportional to the outlet's area. 


\section{Windkessel Parameters}

TABLE E1. Values of the lumped parameter Windkessel boundary conditions for an example patient from each of the 5 groups

\begin{tabular}{|c|c|c|c|c|}
\hline \multirow[b]{2}{*}{ Group } & \multirow[b]{2}{*}{ Outlet } & \multicolumn{3}{|c|}{ Windkessel parameters } \\
\hline & & $\boldsymbol{R}_{p}$ & $\boldsymbol{R}_{d}$ & $C$ \\
\hline \multirow[t]{4}{*}{ Volunteers } & Brachiocephalic artery & 1.36 & 9.23 & 48.3 \\
\hline & Left common carotid artery & 2.46 & 15.3 & 29.2 \\
\hline & Left subclavian artery & 1.74 & 11.3 & 39.3 \\
\hline & Descending aorta & 0.25 & 2.14 & 208 \\
\hline \multirow[t]{4}{*}{ AR-TAV } & Brachiocephalic artery & 0.41 & 9.79 & 22.68 \\
\hline & Left common carotid artery & 2.08 & 39.57 & 5.61 \\
\hline & Left subclavian artery & 1.18 & 24.31 & 9.13 \\
\hline & Descending aorta & 0.10 & 2.79 & 79.58 \\
\hline \multirow[t]{4}{*}{ AS-TAV } & Brachiocephalic artery & 0.48 & 4.91 & 36.22 \\
\hline & Left common carotid artery & 1.73 & 14.81 & 12.00 \\
\hline & Left subclavian artery & 1.65 & 14.19 & 12.52 \\
\hline & Descending aorta & 0.19 & 2.23 & 79.85 \\
\hline \multirow[t]{4}{*}{ AS-BAV(RL) } & Brachiocephalic artery & 0.79 & 18.2 & 28.2 \\
\hline & Left common carotid artery & 1.15 & 24.9 & 20.5 \\
\hline & Left subclavian artery & 1.29 & 27.6 & 18.6 \\
\hline & Descending aorta & 0.17 & 4.69 & 109 \\
\hline \multirow[t]{4}{*}{$\mathrm{AS}-\mathrm{BAV}(\mathrm{RN})$} & Brachiocephalic artery & 0.67 & 5.61 & 49.28 \\
\hline & Left common carotid artery & 2.38 & 16.49 & 16.77 \\
\hline & Left subclavian artery & 2.00 & 14.22 & 19.45 \\
\hline & Descending aorta & 0.20 & 2.01 & 137.90 \\
\hline
\end{tabular}

The units of resistance are $10^{3}$ dynes s/ $\mathrm{cm}^{5}$. The units of capacitance are $10^{-6} \mathrm{~cm}^{5} /$ dynes. $R_{p}$, Proximal resistance; $R_{d}$, distal resistance; $C$, capacitance; $A R-T A V$, aortic regurgitation tricuspid aortic valve; $A S-T A V$, aortic stenosis tricuspid aortic valve; $A S-B A V(R L)$, aortic stenosis bicuspid aortic valve with right left cusp fusion; $A S-B A V(R N)$, aortic stenosis bicuspid aortic valve right non cusp fusion.

\section{APPENDIX E3: HEMODYNAMIC INDICES \\ Helical Flow Index (HFI)}

Aortic 3-dimensional velocity streamlines were calculated from temporally resolved velocity data for the entire thoracic aorta and color coded to represent blood velocity. Helicity is a metric that represents the extent to which corkscrew-like motion occurs and is governed by velocity and vorticity. ${ }^{\mathrm{E} 4} \mathrm{HFI}$ was calculated to quantitatively measure the degree of helicity. $H F I_{P}$ is the helical flow index for each pathline (velocity streamline), calculated over the particle trajectory:

$$
H F I_{p}=\frac{1}{N_{j}} \sum_{i}^{N_{j}} \Psi_{i}
$$

Here, $\Psi_{i}$ is the dimensionless normalized helicity, calculated as the cosine of the angle between velocity and vorticity vectors at each point of the pathline. $N_{j}$ is the number of 0.5 -mm steps, $i=1, \ldots, N_{j}$, along the fluid particle pathline $j$. Steady Poiseuille flow gives a value of $\Psi_{i}=0$, whereas values of $|\Psi|=1$ occur when flow is purely helical. ${ }^{\mathrm{E} 4, \mathrm{E} 5} H F I_{\text {systole }}$ is the average $H F I_{p}$ over all pathlines during peak systole.

\section{Wall Shear Stress (WSS)}

WSS expresses the force per unit area exerted by a flowing fluid on a surface of the lumen in the direction of the local tangent. In a complex 3-dimensional geometry such as the aorta, wall shear stress $\overrightarrow{W S S}$ can be obtained as follows:

$$
\overrightarrow{W S S}=\mu\left(\nabla \vec{u}+\nabla \vec{u}^{T}\right) \vec{n}
$$

where $\mu$ is the blood viscosity, $\nabla \vec{u}$ is the gradient of the velocity field, $\nabla \vec{u}^{T}$ is the transpose of the gradient of the velocity field, and $\vec{n}$ is the unit normal vector to the vessel wall.

\section{Oscillatory Shear Index (OSI)}

In pulsatile flow, the temporal variation in WSS direction can be expressed in terms of the OSI:

$$
\mathrm{OSI}=\frac{1}{2}\left(1-\frac{\left|\int_{0}^{T} w s s_{z} d t\right|}{\int_{0}^{T}\left|w s s_{z}\right| d t}\right)
$$


where an OSI value of zero indicates unidirectional flow throughout the pulsatile cycle, and a value of 0.5 indicates that flow oscillates forward and backward for the same period of time during the cycle (ie, disturbed flow). OSI essentially measures the degree of disturbed flow at the vessel wall, ${ }^{\mathrm{E} 4}$ and has been shown to be associated with vasculopathy. ${ }^{\mathrm{E} 4}$

\section{E-References}

E1. Figueroa CA, Vignon-Clementel IE, Jansen KC, Hughes TJ, Taylor CA. A coupled momentum method for modeling blood flow in three-dimensional deformable arteries. Comput Methods Appl Mech Eng. 2006;195:5685-706.
E2. Vignon-Clementel IE, Figueroa CA, Jansen KE, Taylor CA. Outflow boundary conditions for three-dimensional finite element modeling of blood flow and pressure in arteries. Comput Methods Appl Mech Eng. 2006;195: 3776-96.

E3. Laskey WK, Parker HG, Ferrari VA, Kussmaul WG, Noordergraaf A. Estimation of total systemic arterial compliance in humans. J Appl Physiol. 1990;69:112-9.

E4. Hardman D, Semple SI, Richards JM, Hoskins PR. Comparison of patientspecific inlet boundary conditions in the numerical modelling of blood flow in abdominal aortic aneurysm disease. Int J Numer Method Biomed Eng. 2013; 29:165-78.

E5. Morbiducci U, Ponzini R, Rizzo G, Cadioli M, Esposito A, De Cobelli F, et al. In vivo quantification of helical blood flow in human aorta by time-resolved three-dimensional cine phase contrast magnetic resonance imaging. Ann Biomed Eng. 2009;37:516-31. 